\title{
Article
}

\section{A System for Optimizing the Process of Straw Bale Retrieval}

\author{
Mahdi Vahdanjoo ${ }^{1, * \mathbb{D}}$, Michael Nørremark ${ }^{2}$ and Claus G. Sørensen ${ }^{2}(\mathbb{D}$ \\ 1 Department of Agroecology, Aarhus University, 8830 Tjele, Denmark \\ 2 Department of Electrical and Computer Engineering, Aarhus University, 8830 Tjele, Denmark; \\ michael.norremark@ece.au.dk (M.N.); claus.soerensen@ece.au.dk (C.G.S.) \\ * Correspondence: mahdi.vahdanjoo@agro.au.dk
}

check for

updates

Citation: Vahdanjoo, M.; Nørremark M.; Sørensen, C.G. A System for Optimizing the Process of Straw Bale Retrieval. Sustainability 2021, 13, 7722 https://doi.org/10.3390/su13147722

Academic Editor: Marco Manzone

Received: 11 June 2021

Accepted: 8 July 2021

Published: 10 July 2021

Publisher's Note: MDPI stays neutral with regard to jurisdictional claims in published maps and institutional affiliations.

Copyright: (c) 2021 by the authors. Licensee MDPI, Basel, Switzerland. This article is an open access article distributed under the terms and conditions of the Creative Commons Attribution (CC BY) license (https:// creativecommons.org/licenses/by/ $4.0 /)$.

\begin{abstract}
During a baling operation, the operator of the baler should decide when and where to drop the bales in the field to facilitate later retrieval of the bales for transport out of the field. Manually determining the time and place to drop a bale creates extra workload on the operator and may not result in the optimum drop location for the subsequent front loader and transport unit. Therefore, there is a need for a tool that can support operators during this decision process. The key objective of this study is to find the optimal traversal sequence of fieldwork tracks to be followed by the baler and bale retriever to minimize the non-working driving distance in the field. Two optimization processes are considered for this problem. Firstly, finding the optimal sequence of fieldwork tracks considering the constraints of the problem such as the capacity of the baler and the straw yield map of the field. Secondly, finding the optimal location and number of bales to drop in the field. A simulation model is developed to calculate all the non-productive traversal distances by baler and bale retrieval in the field. In a case study, the collected positional and temporal data from the baling process related to a sample field were considered. The output of the simulation model was compared with the conventional method applied by the operators. The results show that application of the proposed method can increase efficiency by $12.9 \%$ in comparison with the conventional method with edited data where the random movements (due to re-baling, turns in the middle of the swath, reversing, etc.) were removed from the data set.
\end{abstract}

Keywords: optimization; straw collection; baling system; route planning; logistics; precision agriculture; decision support; efficiency

\section{Introduction}

The limited marginal revenue, the increasing costs of agricultural production, and shorter time slots of field operations all require modern agriculture to become more productive in order to handle the growing global demand [1,2]. Biomass as a renewable and clean source of energy has received considerable attention from multiple stakeholders [3-6]. However, there are two main challenges in producing energy from biomass: low bulk density and high logistics costs [7,8]. Therefore, the logistics of biomass is an important factor for the productivity and sustainability of bioenergy production systems $[9,10]$.

A biomass supply chain includes these main processes: harvesting, collecting straw / residues, and pretreatment, storing and transferring biomass to a biorefinery [8,11-13]. The harvesting and collecting systems in the biomass supply chain can be classified into different types like chopping and baling systems [14]. This paper only focuses on the bale hauling system, which is the proper method for harvesting and collecting biomass for the second generation of bioethanol such as grass and wheat straw. The general benefits of the baling system can be listed as follows: easy and controlled logistics, volume reduction, and lower cost of transportation and storage [15]. In order to improve the efficiency of the bale hauling system, all field activities, such as in-field bale aggregation and transportation, should be planned and optimized [9]. 
Precision agriculture is a farming management concept benefitting from applying technologies such as navigation-aid systems, auto-steering technologies, remote sensing, cloud computing, and telecommunication [16-20]. Developing a decision support system for biomass collection and bales aggregation processes can reduce the total traversal distance in the field and increases the total efficiency of the system [21].

In the baling system, usually, the logistics process starts by collecting the biomasses from the field [22]. After harvesting, the balers can compress and compact the residuals in the form of large square bales (e.g., $500 \mathrm{~kg}$ weight and the dimension of $1.2 \times 0.9 \times$ $2.4 \mathrm{~m}$ ) [23]. Bales remain dispersed in the field before stacking them at a specific location close to one of the field's edges or left randomly inside the field. Afterward, those stacked or single bales are transferred to the more permanent storage locations or biorefineries for further processes. The bale collecting problem consists of all the operations related to several agricultural machines and the goal is to determine the best sequence in which to spread the bales over the field and then collect them [24]. Developing the optimization and simulation models for the bale collecting problem can help farmers to decide which solution is the best route for making and collecting the bales in the sense of minimizing the non-working traveled distance/time or the fuel consumption.

The bale collecting problem can be cast as the well-known vehicle routing problem (VRP), in which a single capacitated agent should visit multiple spots (customers) for delivery and it should return to the depot for refilling/unloading [25]. In order to formulate the process of making bales and the further collection as a mathematical model, first, the agricultural field is going to be divided into tracks (swaths) based on the working width of the applied windrower. Afterward, a baler with a bale accumulator is going to cover all those swaths for making bales. This process can be optimized by finding a route through all the swaths to drop the bales in a position that can minimize the total non-working traveled distance/time for the further collection process by considering the capacity of the bale accumulator. Moreover, according to the position of the dropped bales in the field, the collecting process can be optimized by finding an optimal route through the field to collect the bales by considering the capacity of the bale wagon.

The VRP problem is classified as a non-deterministic polynomial-time hardness (NPhardness) problem. Due to the computational difficulty of these types of problems, usually, meta-heuristics algorithms have been developed by researchers to find a near-optimal solution in a reasonable time. The application of VRP for planning the agricultural in-field operation has been demonstrated in several studies [26-31]. Several meta-heuristic algorithms have been developed to solve combinatorial optimization problems such as VRP by considering varying optimization criteria (e.g., minimizing the total non-working distance or operational time). Bochtis et al. [26] presented an algorithmic method (B-patters) to find the optimal sequences of fieldwork tracks for area coverage by agricultural vehicles. They applied the Clarke-Wright savings algorithm to find the optimal sequence of tracks and the results showed reductions in the non-working distance up to $58.65 \%$. Jensen et al. [27] developed an algorithmic approach based on the state-space search technique for the optimization of capacitated field operations. Khosravani Moghadam et al. [28] developed two meta-heuristics algorithms, ant colony optimization, and simulated annealing, and compared the functionality of these two algorithms by applying them in a benchmark field.

This paper presents a meta-heuristics algorithm, simulated annealing, to solve the problem of finding the optimal location for dropping the bales inside a field and the optimal number of dropped bales in each position. The proposed method aims to improve the total field efficiency for bale retrieval operations by providing a decision support tool that helps the operator of the baler to decide how many bales to drop at which location.

\section{Materials and Methods}

\subsection{Problem Definition}

During a baling operation, swaths of straw from harvested crops or whole crops are compressed into bales. When a bale is formed, it may be automatically dropped in the 
field directly following completion thereof or commanded to be dropped therefrom by an operator of the baler at a time and location chosen by the operator. Operators often desire to pick when and where to drop a bale to facilitate later retrieval of the bale for transport out of the field. Manually determining the time and place to drop a bale creates extra work for the operator and may not result in the optimum drop location for the subsequent front loader and transport unit. Therefore, there is a need for an improved method and apparatus for determining when and where to drop bales in a field. Estimating the number of bales and the position of each bale will improve the selection of bale size and further decisions about the type and the number of required transport units such as trailer or truck. Additionally, it is expected that there are savings to be achieved from optimized route planning for the baler in the field.

\subsection{Bales In-Field Layout Planning}

In the collecting operation, a baler collects the residues from the swaths and compress them to make bales. The last part of the baling process is wrapping or tying the compressed residues and after that the produced bale will directly drop on the ground or goes into a bale collector dragged behind the baler. The bale collectors enable balers to transport and unload a certain number of bales onto the ground. Once the maximum load capacity in the bale collector is reached, the unloading process take place automatically. In a case that the baler reaches the end of a swath before completing a bale or when there is enough space in the bale collector, the operation is continued after turning into the next swath. In this study, the desired pattern for the in-field layout of the bales is placing them on the virtual lines that are perpendicular (90 degree) with the direction of the swaths. The mentioned pattern is demonstrated in Figure 1.

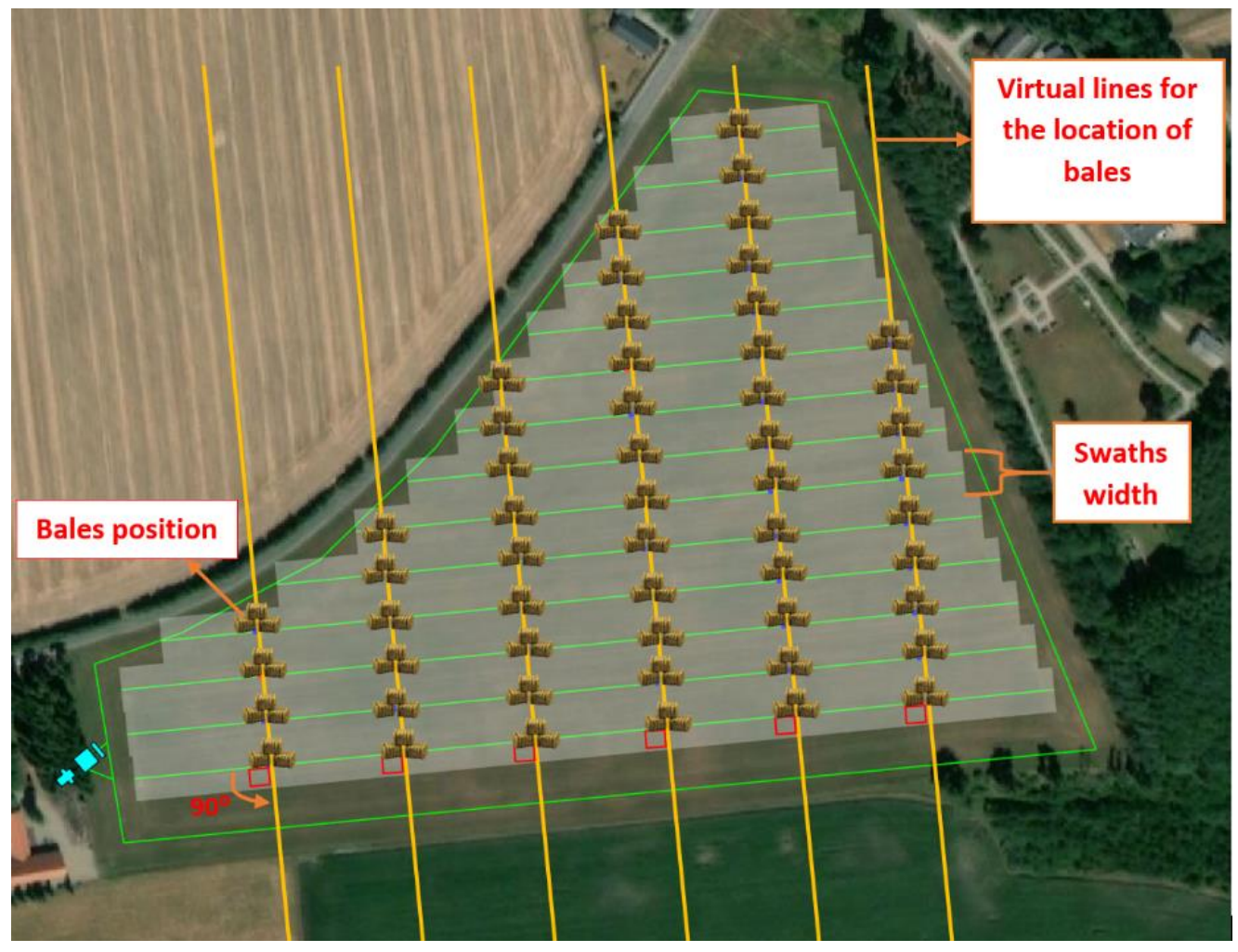

Figure 1. Required pattern for bale drops (in-field layout). 


\subsubsection{Correlation between Crop Yield and Number of Bales}

The amount of collected residues by a baler is a function of the desired bale size and bulk density of biomass material. Therefore, the total number of bales can be determined based on the following formula:

$$
\text { NBales }=\frac{A_{h a} \times Y_{h a}}{M_{b}}
$$

where $A_{h a}$ is the field area (hectare); $Y_{h a}$ is the dry biomass yield (ton/hectare); and $M_{b}$ is the bale dry mass (ton).

The amount of traveled distance by a baler to generate one bale (DBales) can be estimated based on the following formula:

$$
\text { DBales }=\frac{T L S}{\text { NBales }}
$$

where TLS is the total length of swaths and NBales is the total number of bales.

The total length of swaths (TLS) can be estimated by dividing the field area $\left(\mathrm{m}^{2}\right)$ by the swath width $(S)$.

$$
T L S=\frac{A}{S}
$$

2.2.2. Determine the Minimum Number of Virtual Lines That Define the Dropping Location of Bales

The longest fieldwork track (swath) derived from the field polygon is considered as a reference line for calculating the required number of virtual lines (VL). Equation (4) determines the number of bales in the longest swath:

$$
N B L S=\left\lfloor\frac{L L S}{\text { DBales }}\right\rfloor
$$

where LLS is the length of the longest swath and DBales is the amount of traveled distance by a baler to generate one bale. The minimum number of virtual lines (VL) calculated by Equation (5):

$$
\text { NLines }=\frac{N B L S}{C}
$$

where NBLS is the number of bales in the longest swath and $C$ is the capacity of the bale collector. The VLs divide the longest swath into several parts. The number of divided parts is equal to the number of lines plus one. The length of each part is determined by the following formula:

$$
L p=\frac{L L S}{\text { NLines }+1}
$$

The following formula shows how to check whether the number of VLs are enough to let the baler cover the longest swath and drop the bales on the defined VLs:

$$
\begin{gathered}
\text { If }: \text { NBLS }-\left\lfloor\frac{\text { NLines } \times \text { Lp }}{D \text { Bales }}\right\rfloor<C \rightarrow(\text { NLines }=\text { NLines }) ; \\
\text { Else }:(\text { NLines }=\text { NLines }+1)
\end{gathered}
$$

\subsubsection{Determine the Coordinates of the Bales Dropping Location}

In this study, the intersect points between swaths and VLs define the dropping location for bales. The procedure for finding the coordinates of the bale dropping locations are listed as follows: First of all, to be sure that the VLs can be projected on all the swaths, the longest swath in the field is going to be extended from both sides (top and down) until it reaches the in-field boundaries. As a result, a line segment $A B$ is generated and is going to be divided based on the length of the parts calculated by Equation (6). Figure 2 shows how to divide the longest swath in the field. 


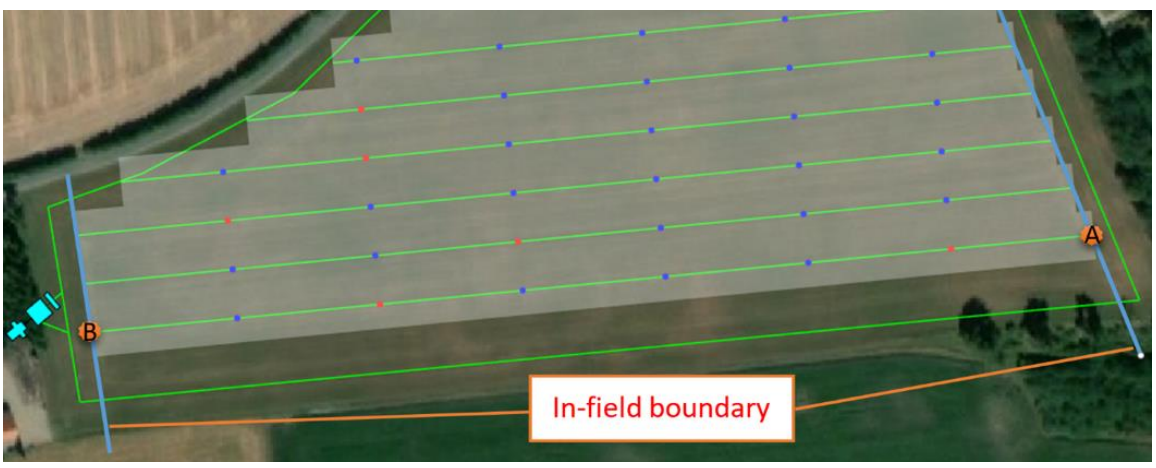

Figure 2. Dividing the longest swath into parts.

The number of divisions for line $\mathrm{AB}$ can be determined using the following formula:

$$
N \operatorname{div} A B=\left\lfloor\frac{L_{A B}}{L p}\right\rfloor
$$

where $L_{A B}$ is the length of the line $\mathrm{AB}$ and is equal to the Euclidean distance between points $\mathrm{A}$ and $\mathrm{B}$.

The coordinates of each division point can be determined by applying the steps in the following diagram (Figure 3):

$$
\begin{gathered}
\Delta x=\frac{i \times L p \times \mid \text { Latitude }_{B}-\text { Latitude }_{A} \mid}{L_{A B}} ; i=1,2, \ldots, N \operatorname{Niv} A B \\
\Delta y=\frac{i \times L p \times \mid \text { Longitude }_{B}-\text { Longitude }_{A} \mid}{L_{A B}} ; i=1,2, \ldots, N \operatorname{Ndiv} A B
\end{gathered}
$$

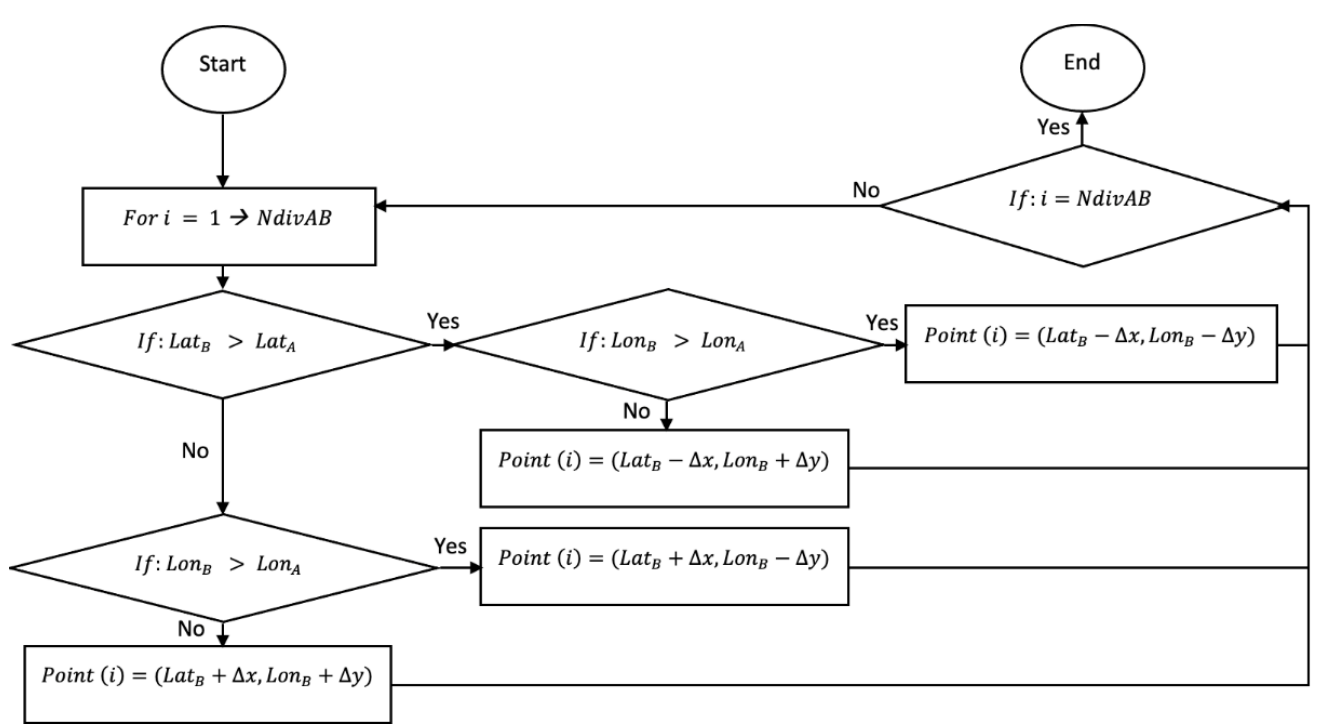

Figure 3. Summary of the steps to calculate the coordinates of the division points on the AB line.

After determining the coordinates of the division points in the $\mathrm{AB}$ line, the next step is to project lines from each division point (on the $\mathrm{AB}$ line) to the other swaths inside the field. The slope of projected lines can be calculated based on the slope of swaths. Equation (11) shows how to calculate the slope of projected lines.

$$
\operatorname{slpProjL}=-\left(\frac{1}{\frac{\sum s l p S w t}{n}}\right), n=\text { number of swaths }
$$


The equation of swaths can be determined based on the coordinates of swaths' nodes as follows:

$$
\begin{gathered}
Y-y_{1}=\left(\frac{y_{2}-y_{1}}{x_{2}-x_{1}}\right)\left(X-x_{1}\right) \\
Y-y_{1}=\operatorname{slp} \operatorname{ProjL}\left(X-x_{1}\right)
\end{gathered}
$$

where, $\left(x_{1}, y_{1}\right)$ are the coordinates of the division points on the $\mathrm{AB}$ line. By determining the equation of swaths and projected lines, the coordinates of all the intersection points located inside the field can be calculated by solving Equations (12) and (13) for each pair of swaths and projected lines. These intersection points define the locations of dropping bales inside the field.

\subsubsection{Determine the Number of Bales in Each Dropping Location}

After determining the location for dropping the bales, it is necessary to calculate the number of released bales in those locations. The following diagram (Figure 4) summarizes the steps to determine the number of bales in each dropping location.

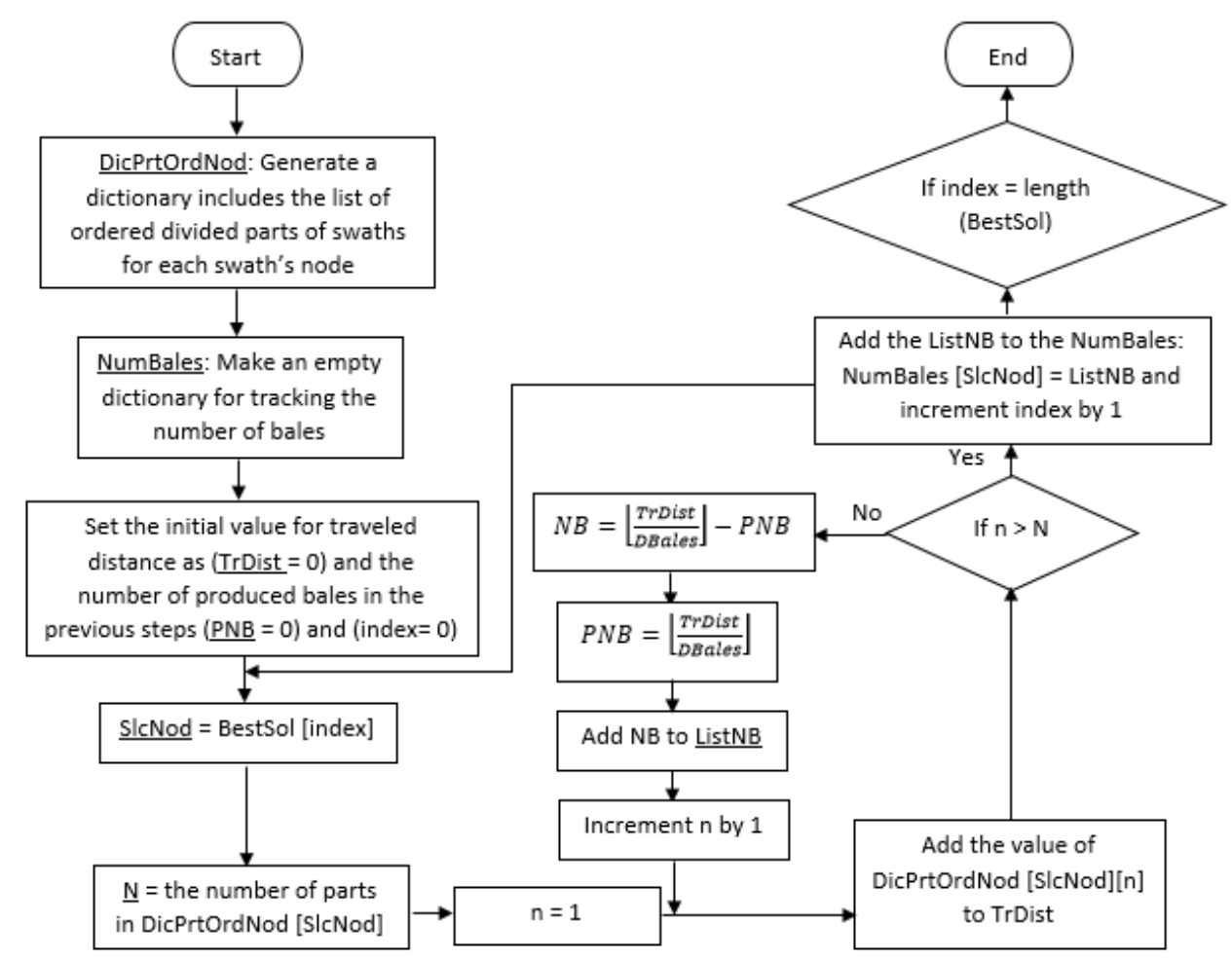

Figure 4. The overview of the steps to determine the number of bales in each dropping location.

\subsection{Field Representation Model}

A field representation model is developed to generate a geometrical representation of the target field. One of the common methods in this concept is using the spatial configuration planning approach, which applies the geometric primitives to represent the field. This method consists of three tasks: First, representing the field with simple geometry shapes; second, determining the driving direction in the field and third, generating the work areas (tracks) based on the driving direction. The output from this method is a set of line segments or polylines that depict the field boundaries, obstacles, fieldwork areas, and headland passes that can be followed by the machine [2,30]. These outputs can be used to generate a field graph consisting of all the edges in the field with their corresponding weight (which is the actual length of the edge). Further, the field graph can be used to make a cost matrix for a field. Figure 5 demonstrates the overview of the field representation model. 


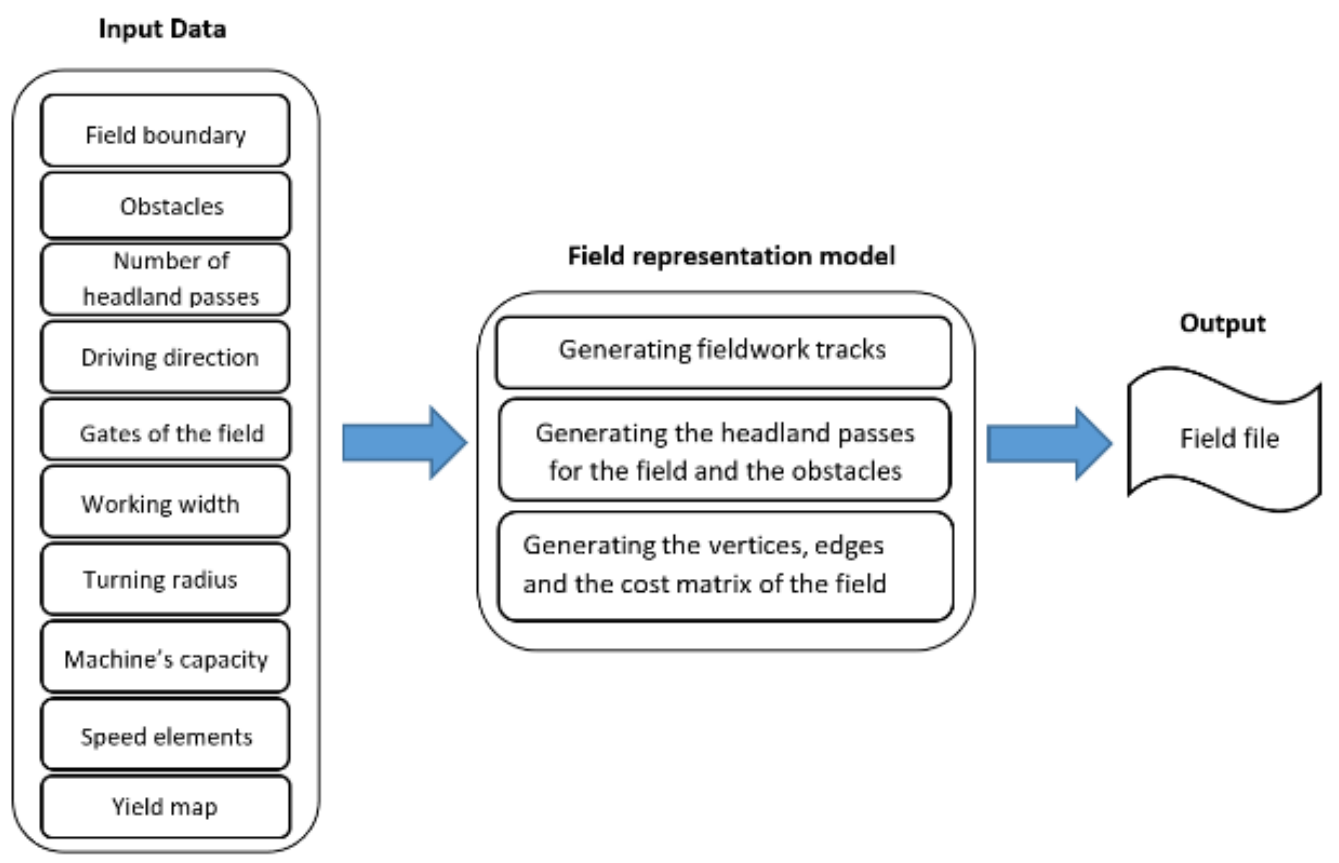

Figure 5. The overview of the field representation model.

\subsection{Optimization Model}

The problem explored in this study is to find the optimal traversal sequence of fieldwork tracks to follow by a baler and collector to minimize the non-working driving distance in the field. The objectives of this study are listed as follows: first, the application of route planning for the baler by considering the constraints of the problem such as the capacity of the baler and the yield of the field. Second, find the number of bales and the location of them inside the field. Figure 6 shows the overview of the optimization model. There are different approaches to finding the location of bales inside the field. The first method is clustering, which is a way of locating the bales close to some predefined centers in the field. The second approach, which is proposed in this study, is trying to locate bales in straight lines. In this approach based on the capacity of the baler and the estimated traveled distance for making one bale, the number of lines was calculated and each time that baler reaches the intersect points, it can drop some bales on the ground. The meta-heuristic algorithm simulated annealing (SA) is applied to find the local optimum solution for this problem. The optimization model was developed using the PYTHON programing language (version 3.7) [32].

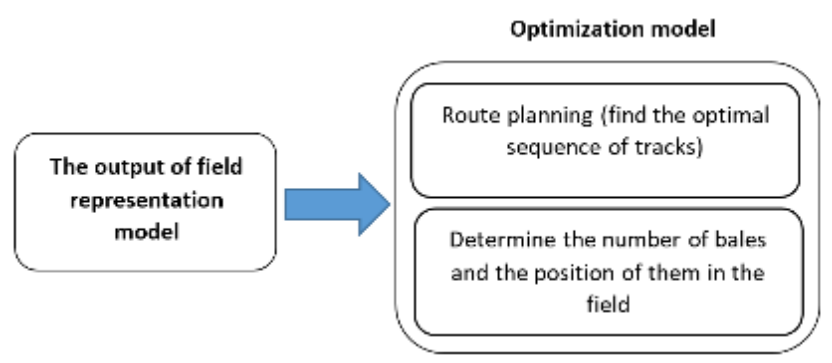

Figure 6. The overview of the optimization model.

\subsubsection{Simulated Annealing (SA) Algorithm}

The simulated annealing, as a stochastic algorithm, is implemented in several problems in various fields such as computer design, route planning, image processing, etc. The performance structure of this algorithm is based on the simulation of the cooling process, which is called annealing, where a solid is gradually cooled. The values related to the 
primary features of the SA algorithm such as the initial temperature, cooling rate, and termination policy, are empirically defined and showed in Table 1.

Table 1. Primary features of the simulated annealing (SA) algorithm.

\begin{tabular}{ccccc}
\hline $\begin{array}{c}\text { Primary } \\
\text { Features }\end{array}$ & Main Iterations & $\begin{array}{c}\text { Internal } \\
\text { Iterations }\end{array}$ & $\begin{array}{c}\text { Initial } \\
\text { Temperature }\left({ }^{\circ} \mathbf{C}\right)\end{array}$ & Cooling Rate \\
\hline Values & 1000 & 60 & 200 & 0.9 \\
\hline
\end{tabular}

For each annealing iteration, the temperature is reduced in some sub iterations where the current temperature is multiplied by the cooling rate. The algorithm starts with an initial solution and for each sub iteration, it evaluates the current solution against a modified solution using a neighborhood operator [2,28]. An overview of the SA algorithm is demonstrated in Figure 7.

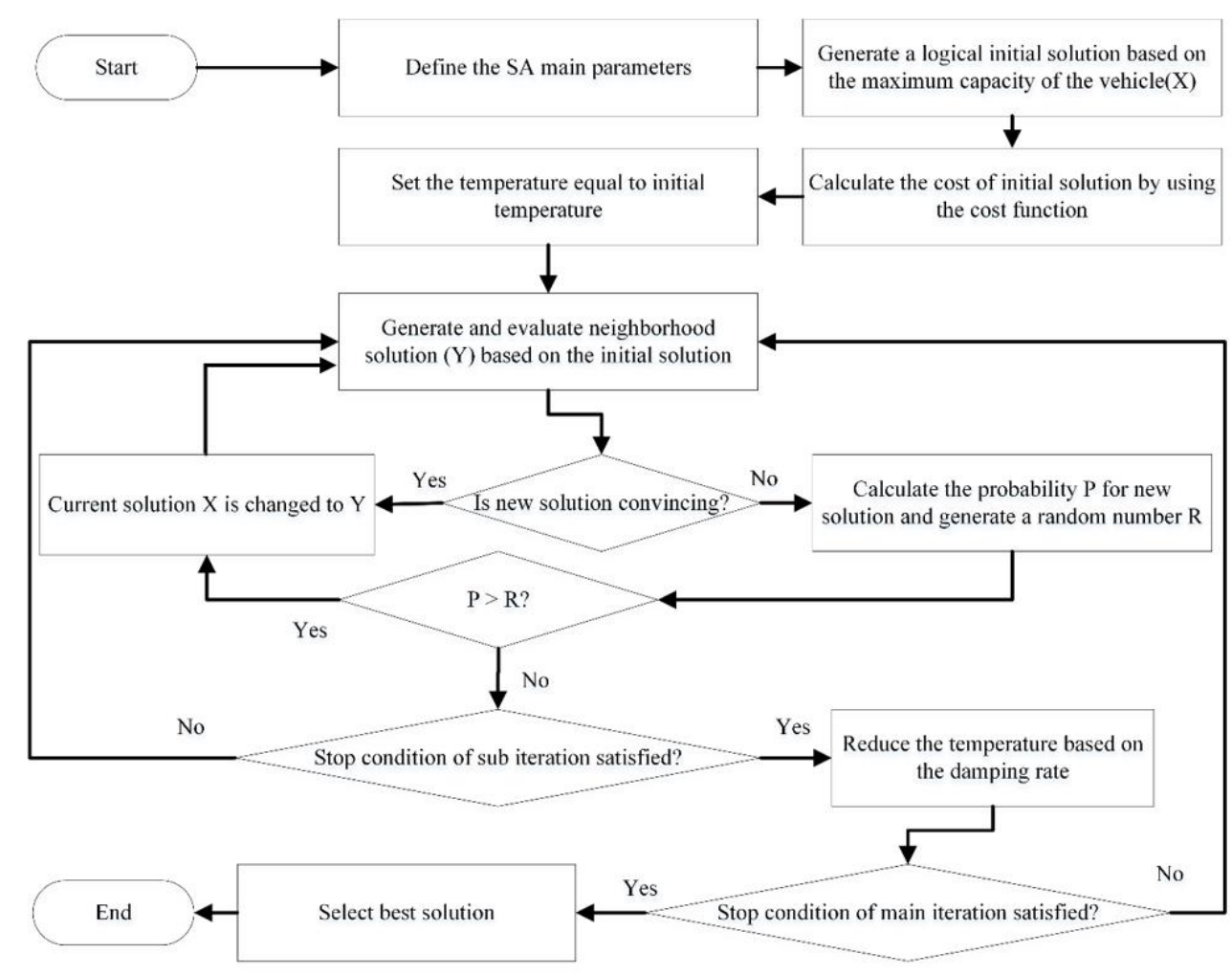

Figure 7. An overview of the simulated annealing (SA) algorithm.

\subsubsection{Neighborhood Operators}

In the simulated annealing (SA) algorithm, a new solution can be generated by applying neighborhood operators (random swaps, random swaps of subsequences, random insertions, random insertions of subsequences, reversing a subsequence, and random swaps of reversed subsequences). Table 2 demonstrates the functionality of these operators.

\subsubsection{Initial Solution Generation}

The initial solution in this application of the SA algorithm is a tour that includes a sequence of nodes to be visited by a baler in order to cover all the swaths inside a field. Figure 8 helps to better understand the steps for generating an initial solution. 
Table 2. Neighborhood operators. Numbers with bold changed after applying the neighborhood operator.

\begin{tabular}{cccccccccccccc}
\hline \multicolumn{1}{c}{ Random Swaps } & \multicolumn{1}{c}{ Random Swaps of Subsequences } \\
\hline 0 & $\mathbf{3}$ & 8 & 2 & $\mathbf{5}$ & 1 & 0 & 0 & $\mathbf{3}$ & $\mathbf{8}$ & 2 & $\mathbf{5}$ & $\mathbf{1}$ & 0 \\
0 & $\mathbf{5}$ & 8 & 2 & $\mathbf{3}$ & 1 & 0 & 0 & $\mathbf{5}$ & $\mathbf{1}$ & 2 & $\mathbf{3}$ & $\mathbf{8}$ & 0 \\
\hline \multicolumn{1}{c}{ Random insertions } & \multicolumn{8}{c}{ Random insertions of subsequences } \\
\hline 0 & 3 & 8 & 2 & 5 & $\mathbf{1}$ & 0 & 0 & 3 & 8 & $\mathbf{2}$ & $\mathbf{5}$ & 1 & 0 \\
0 & 3 & $\mathbf{1}$ & 8 & 2 & 5 & 0 & 0 & $\mathbf{2}$ & $\mathbf{5}$ & 3 & 8 & 1 & 0 \\
\hline \multicolumn{1}{c}{ Reversing a subsequence } & & Random swaps of reversed subsequences \\
\hline 0 & 3 & 8 & $\mathbf{2}$ & $\mathbf{5}$ & $\mathbf{1}$ & 0 & 0 & 3 & $\mathbf{8}$ & $\mathbf{2}$ & $\mathbf{5}$ & $\mathbf{1}$ & 0 \\
0 & 3 & 8 & $\mathbf{1}$ & $\mathbf{5}$ & $\mathbf{2}$ & 0 & 0 & 3 & $\mathbf{2}$ & $\mathbf{8}$ & $\mathbf{1}$ & $\mathbf{5}$ & 0 \\
\hline
\end{tabular}

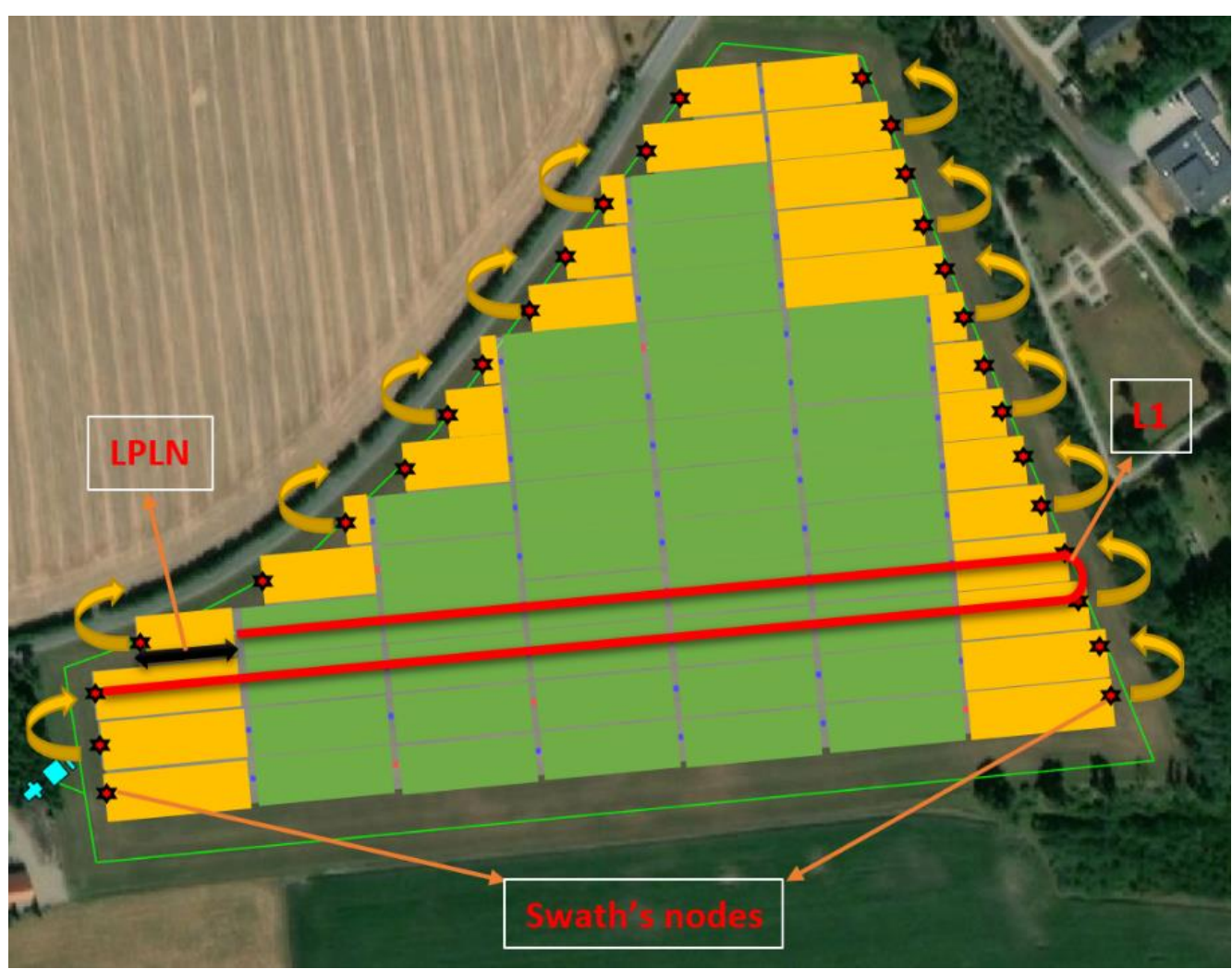

Figure 8. Swath's nodes (red stars) and divided parts (yellow parts); L1: Total traveled distance exclusive of the last divided part of the last swath; LPLN: The length of the divided part belongs to the LastNod.

The following diagram (Figure 9) summarizes the process of generating an initial solution:

\subsubsection{Cost Matrix Generation}

The cost matrix can be used for evaluating the quality of the generated solution by the algorithm. The element of the cost matrix represents the transition cost between every pair of vertices of the field graph. The cost matrix is square $(n \times n)$ with an element $C_{i j}$ which represents the transition cost from vertex $i$ to vertex $j$, where $i \neq j$; otherwise, the cost is equal to $0[2,30]$. The shortest path selected by the Dijkstra algorithm [33] was applied for calculating the transition cost between every pair of nodes. The corresponding transitional cost for a solution can be calculated based on the following formula:

$$
T C=\sum_{i, j} C_{i j}, \forall i, j \in(\text { field's vertices })
$$




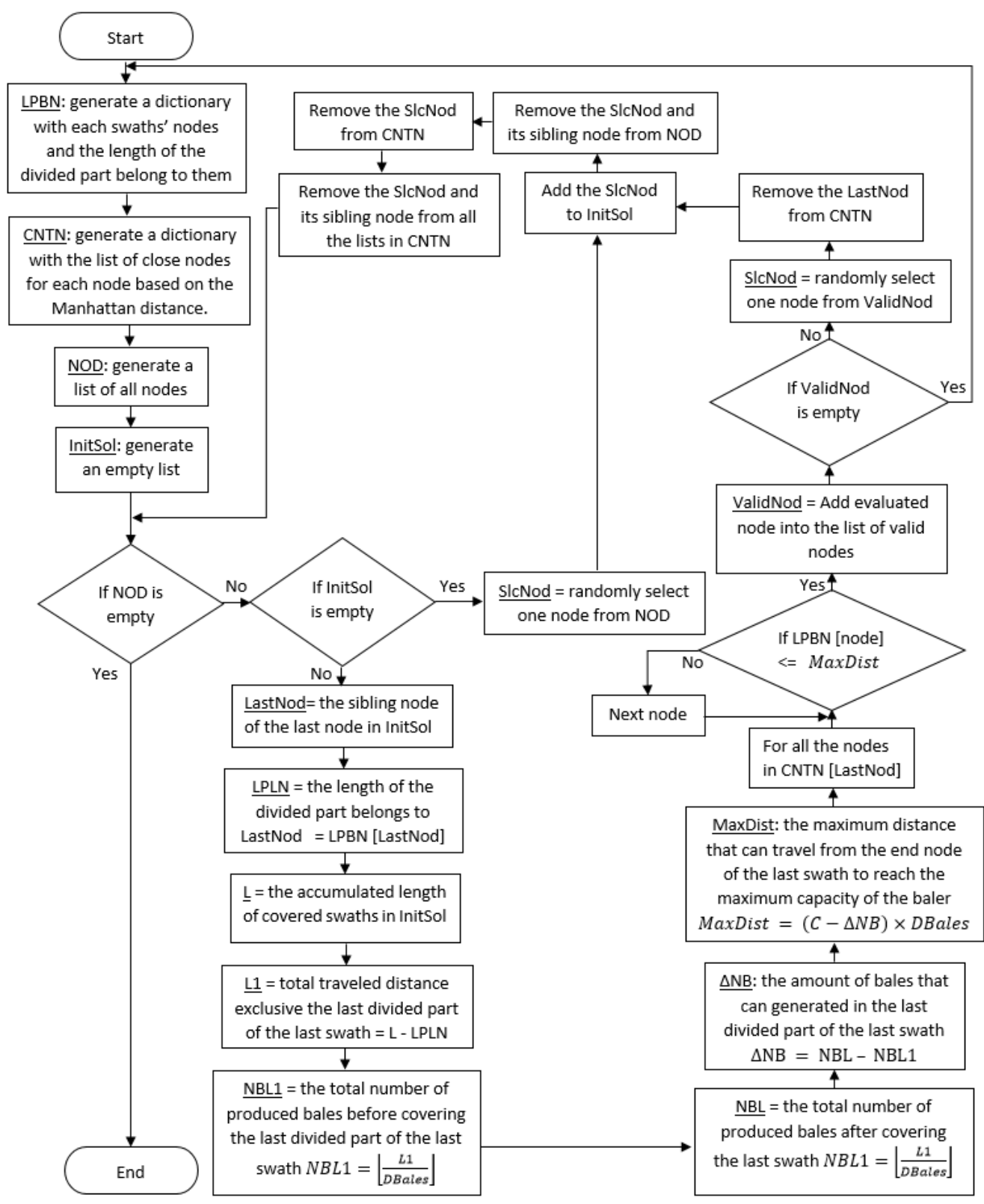

Figure 9. An overview of the process of generating an initial solution.

\section{Results}

\subsection{Case Study}

An agricultural field was considered as a case study to demonstrate the efficiency derived from applying the proposed optimization method to the bale production and collection operations. The location of the field is presented in the following figure (Figure 10). The field size is 79.37 hectares and the baling operation was done by two balers. The baler type was a Krone BigPack 1290 HDP II XC large square baler, with a working width of $10.5 \mathrm{~m}$ determined by the combine harvester swath width, and with a Kinematic turning radius of $7.6 \mathrm{~m}$, producing bale sizes of $1.2 \mathrm{~m} \times 0.9 \mathrm{~m} \times 2.7 \mathrm{~m}$ with an average weight of $580 \mathrm{~kg}$. A POMI bale collector was attached behind the baler to transport and unload up to three bales. Once the third bale was finished and stored on the POMI bale collector, the maximum load capacity in the number of bales was reached and the unloading had to take place. The position of the tractor pulling a baler were registered with Aplicom A1 units (Aplicom Oy, Äänekoski, Finland) and sent wirelessly via a GPRS network to a server and IoT platform (Clara Cloud, Conpleks A/S, Tokyo, Japan). The position of the baler during 
the operation was recorded at $0.5 \mathrm{~Hz}$. The position of individual bales left behind by the baler on the fields was manually measured by RTK-GPS. Data were inspected manually in QGIS, e.g., double registrations of bales were removed. Data for the balers' route was retrieved from the Clara Cloud IoT platform. The coordinate transformation from WGS84 latitude and longitude to UTM Northing and Easting was done by the Danish KMS Trans2 tool (Agency for Data Supply and Efficiency).

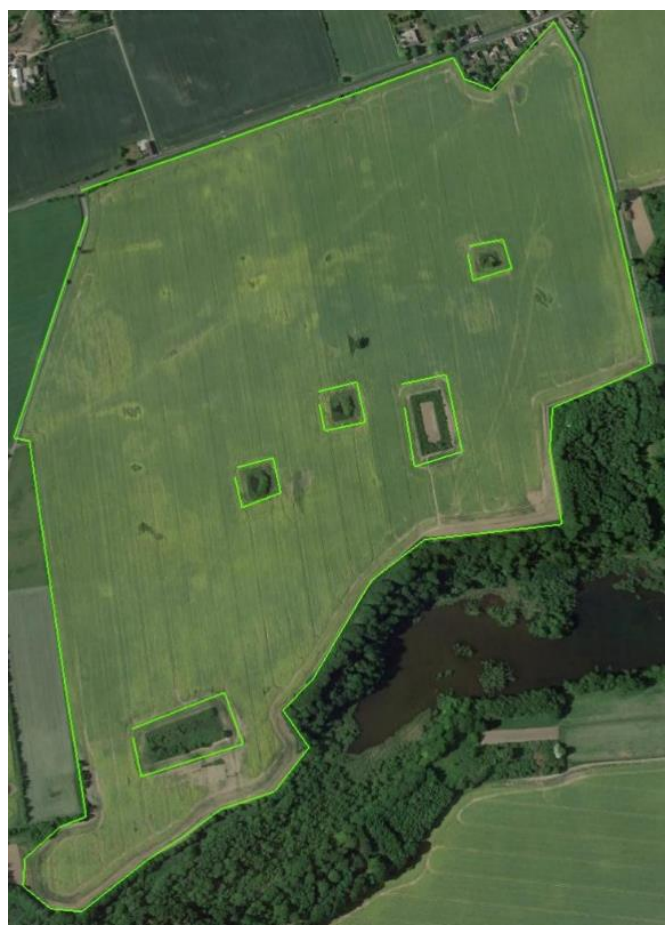

(a)

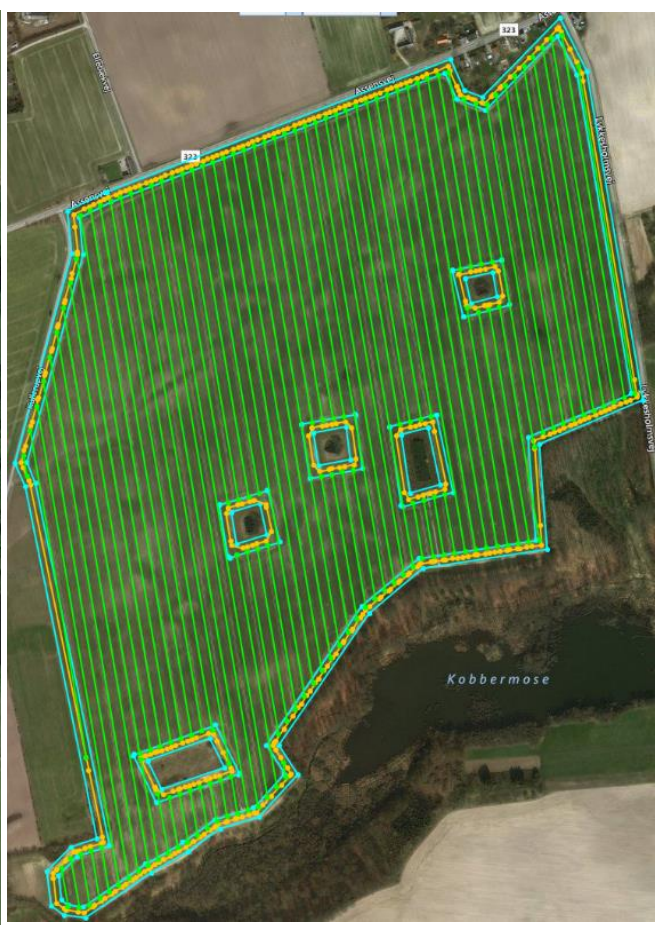

(b)

Figure 10. The case study field with size: 79.37 ha; (a) Representing the field boundary and obstacles inside the field; (b) Field representation after partitioning the field.

The grain yield was registered by yield sensors on a CLAAS Lexion 770 combine. The yield sensor was calibrated according to the combined instruction manual on the day of the harvest of the field. The straw yield can be estimated with the multiplication of the median of the crop yield per field by the straw-weight in the percentage of crop yield. The median of the crop yield can be calculated by the yield logging from the combine, which is equal to 9.46 (ton/hectars). The straw-weight percentage of crop yield is dependent on the local field conditions and the crop variety. For this sample field it is equal to $33.9 \%$.

\subsection{Determine the Driving Distance in the Sample Field}

To calculate the traveled distance by a baler inside the sample field, the recorded GPS data from the baler was considered. In the first step, the recorded coordinates of the bale position were used to make a shapefile and then to plot the location of bales in the QGIS software. The source coordinate reference system was set to (EPSG: 25832-ETRS89/UTM zone $32 \mathrm{~N}$ ) to precisely show the location of bales in the sample field. Figure 11 (1st step) illustrates the location of bales in the sample field. The next step is to use the log file to demonstrate the driving patterns of the baler inside the field. In this way, the coverage of the field, as well as the paths and the maneuvers of the baler, can be studied. Each line of the log file refers to an event that has a time and two coordinates to show the location of the baler at that specific time. To define the direction of traveling inside the paths, different parameters should be calculated in advance. The first one is the amount of traveled distance between two events, which can be calculated as the Euclidean distance of the sequential events. The second parameter is the forward speed of the baler, which can 
be determined by dividing the traveled distance by the duration of time between events. The direction of travel in degrees (0-360) was determined by first calculating the distance between the subsequent position in the Northing $(\mathrm{Y})$ and Easting $(\mathrm{X})$ direction individually. Second, a calculation of the degree of the direction of travel is carried out by adding $\pi$ or $2 \pi$ depending on the sign of the distances in the $X$ and $Y$ direction, which affiliates the direction within quadrants of the unit circle. The direction of driving paths can be defined based on the calculated heading degree. To better study the movement of the baler inside the field, each event was labeled by a number based on its order in the log file. Figure 11 (2nd step), demonstrates the chronological order of events in the log file of the sample field. In the 3rd step, the QGIS plugin "POINTS TO PATH" was applied to plot the paths (driving lines) inside the field. Driving lines could be useful to show the type of maneuvers in the headland part as well as to determine the turning radius of the baler.

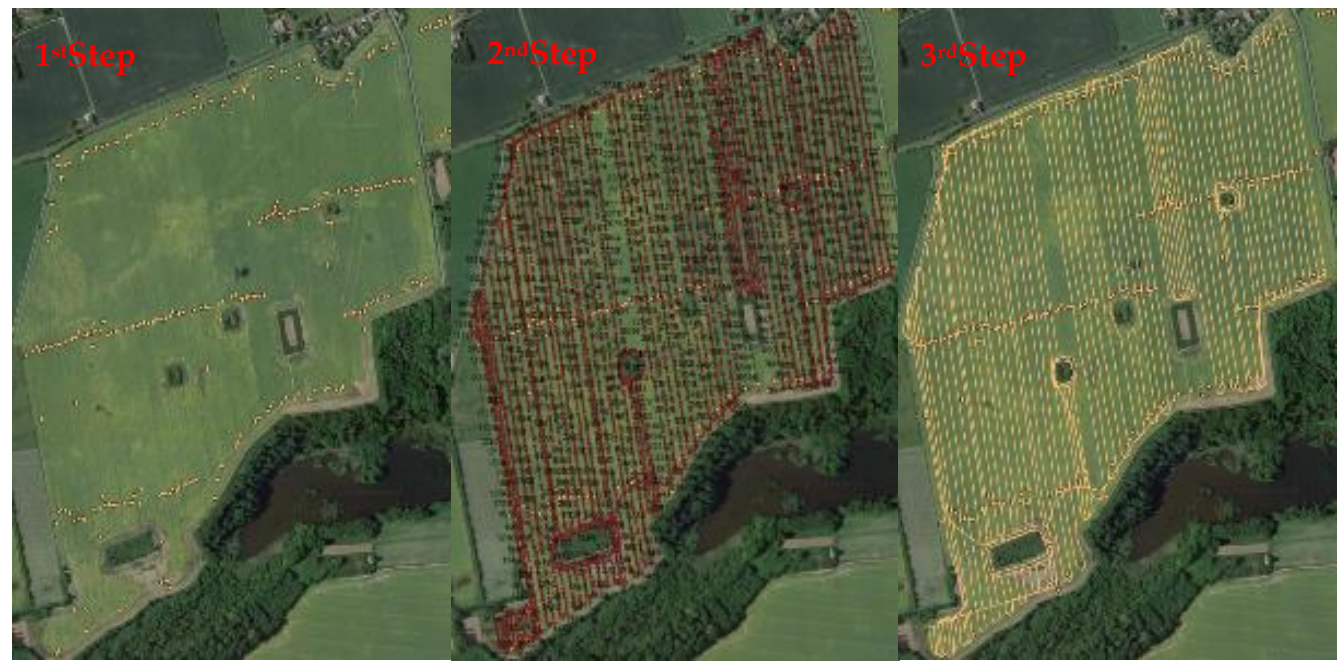

Figure 11. The steps for determining the driving distance in the sample field.

In order to validate the proposed method, the non-working traveled distance for the conventional method was calculated and compared with the solution derived from the proposed optimization algorithm. Therefore, the recorded log file for the sample field was analyzed to determine the total amount of non-working traveled distance. The amount of covered area in the conventional method is calculated by multiplying the total traveled distance by the baler into the working width of the baler $(51,370.8 \times 10.5)$. The same procedure was applied to the optimization method to find the area covered $(64,346 \times 10.5)$. The difference between the area covered in the conventional and optimized methods refers to the fact that in the conventional method the field was covered by two balers and the information corresponding to only one of them was available. However, in the optimized method, the entire field was covered by one baler. Dividing the total driven non-working distance by the amount of covered area shows the amount of non-working distance per hectare, which can be used later for comparison of the optimized and conventional methods. Table 3 demonstrates the comparison between optimized and conventional method.

Table 3. Comparison between the optimized and conventional method for the sample field.

\begin{tabular}{cccc}
\hline Method & $\begin{array}{c}\text { Non-Working } \\
\text { Distance (Meter) }\end{array}$ & $\begin{array}{c}\text { Amount of Covered } \\
\text { Area (ha) }\end{array}$ & $\begin{array}{c}\text { Non-Working Distance } \\
\text { Per Hectare (Meter/ha) }\end{array}$ \\
\hline Conventional & 9694 & 53.9 & 179.8 \\
Optimized & 10,571 & 67.5 & 156.6 \\
\hline
\end{tabular}

The comparison of non-working distance per hectare shows that the optimization model can bring $12.9 \%$ efficiency in comparison with the conventional method in this field. 


\subsection{Scenarios}

Different scenarios were defined to investigate the effects of the number of dropping lines and the location of aggregating points on the total non-working distance and operational time of the baler and collector. The machine considered for in-field hauling is a self-propelled, self-loading unit with the capacity to handle eight bales (big square four $x$ four) at a time. This machine loads with a tilting action, which allows non-stop bales to pick up their speed up to 7 miles per hour. The traveled distance and time for the collector are calculated based on the defined aggregating point in the field.

\subsubsection{Number of Dropping Lines}

Six different scenarios based on the number of dropping lines were defined to better study how this factor affects the total traveled distance/time of the baler or collecting unit. Figure 12 shows each scenario with the corresponding dropping lines. The position of bales is represented by dots on the dropping lines. The color of the dots illustrates the number of dropped bales in that position, which is red for one bale, blue for two bales, and black for three bales.

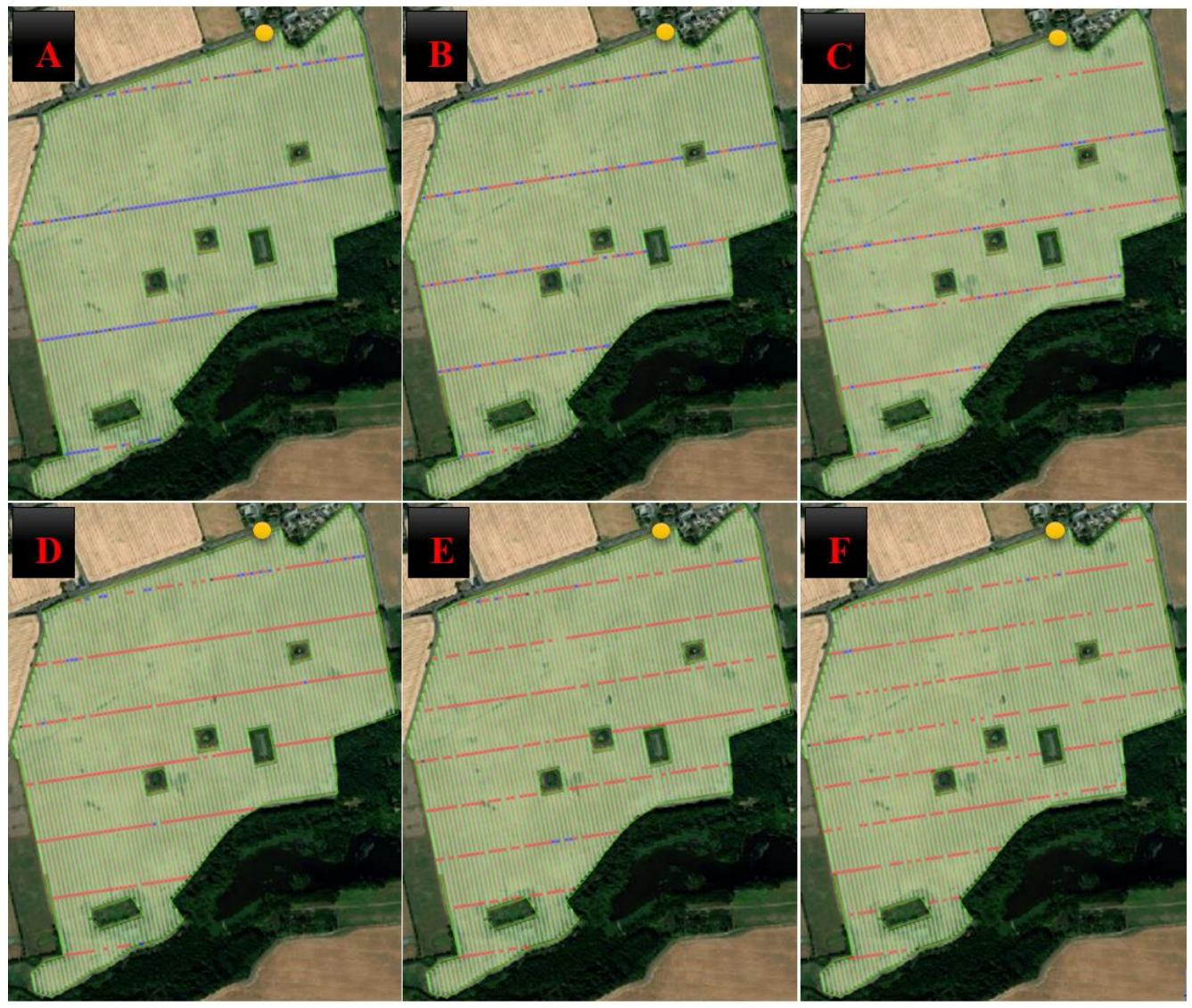

Figure 12. Defined scenarios based on the number of dropping lines in the sample field. (A): four lines. (B): five lines. (C): six lines. (D): seven lines. (E): eight lines. (F): ten lines. The yellow point represents the bales aggregating point in the field.

The results of the simulation model for each scenario are represented in Table 4 .

Figure 13 demonstrates the amount of traveled distance and time for all the defined scenarios. The comparison shows that the lowest traveling distance and time for the baler belongs to the last scenario with 10 dropping lines inside the field. Moreover, the amount of traveled distance and time for the collecting unit was calculated based on each defined scenario. The yellow dot in Figure 12 represents the aggregating point for the sample field. 
The results of the simulation model for collecting the bales inside the sample field are presented in Table 5.

Table 4. The comparison of scenarios for the number of dropping lines for the baler.

\begin{tabular}{ccc}
\hline Scenarios & $\begin{array}{c}\text { Non-Working } \\
\text { Time (Minutes) }\end{array}$ & $\begin{array}{c}\text { Non-Working } \\
\text { Distance (Meter) }\end{array}$ \\
\hline 4 lines & 243.3 & 55,758 \\
5 lines & 222 & 50,999 \\
6 lines & 93.4 & 21,403 \\
7 lines & 90.7 & 20,784 \\
8 lines & 72.8 & 16,686 \\
10 lines & 46.1 & 10,571 \\
\hline
\end{tabular}

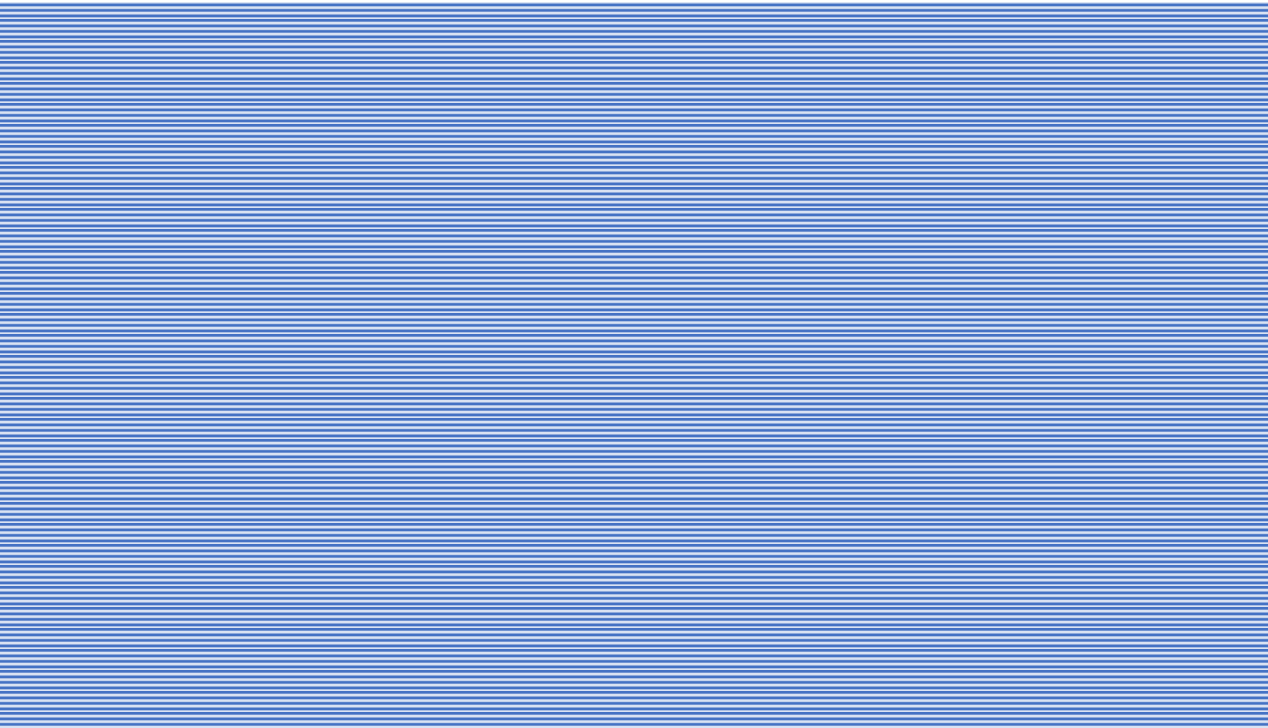

Figure 13. The comparison of the baler's travel time and distance for the defined scenarios based on the number of dropping lines in the field.

Table 5. The comparison of defined scenarios for travel time and distance of the collecting unit.

\begin{tabular}{ccc}
\hline Scenarios & $\begin{array}{c}\text { Non-Working } \\
\text { Time (Minutes) }\end{array}$ & $\begin{array}{c}\text { Non-Working } \\
\text { Distance (Meter) }\end{array}$ \\
\hline 4 lines & 332.4 & 61,824 \\
5 lines & 315.6 & 58,707 \\
6 lines & 341.8 & 63,577 \\
7 lines & 332.1 & 61,763 \\
8 lines & 349.8 & 65,063 \\
10 lines & 350.8 & 65,247 \\
\hline
\end{tabular}

According to Figure 14, the second scenario with 5 lines has the lowest amount of traveled distance and time among the other scenarios for the collecting units.

The important factor in decision making between these scenarios is whether or not the baling process is more critical than the collecting process. Since there is usually a shorter time window for bail processing then bail collecting, it is better to focus on optimizing the baler movements and choose the last scenario with 10 lines. Moreover, Figure 14 shows that the differences between traveled distance and time in each scenario for the collector are much smaller than the baler, which again gives more attention to the baling process rather than the collecting. 


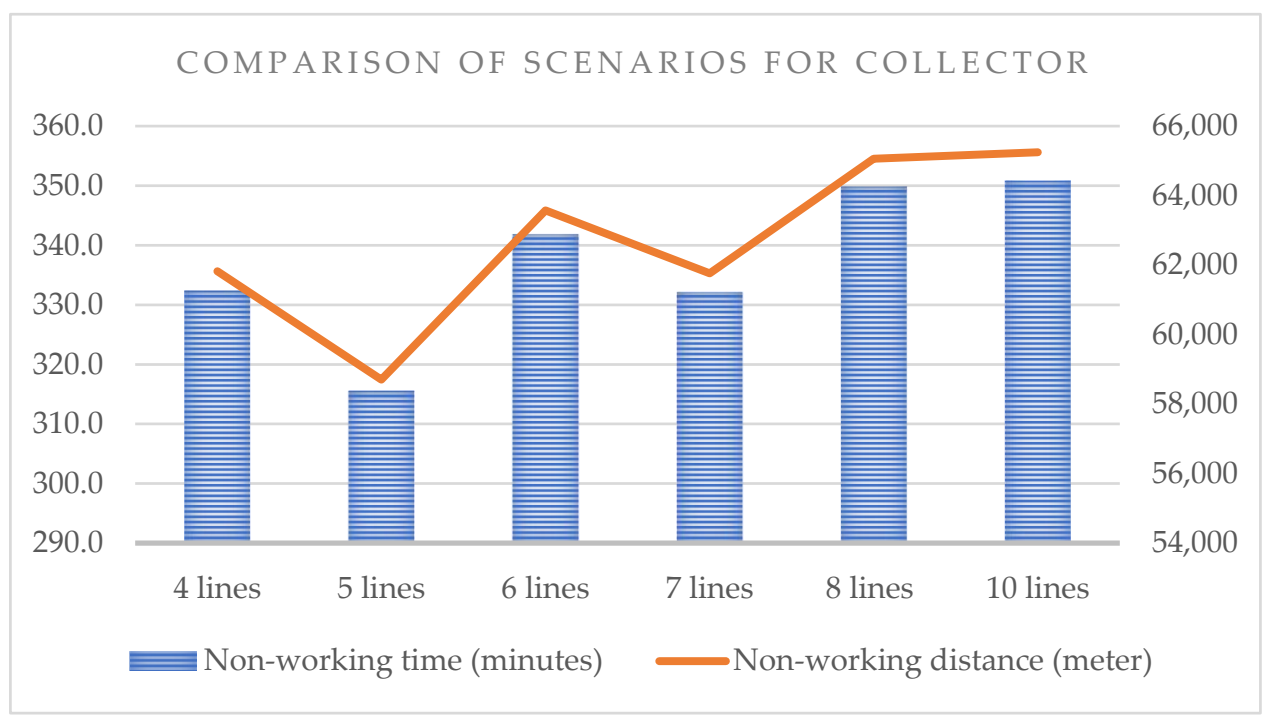

Figure 14. The comparison of the collector's travel time and distance for defined scenarios based on the number of dropping lines in the field.

\subsubsection{The Number and Location of Aggregating Points}

Selecting a location for aggregating the bales inside the field is an important factor that can affect the amount of travel time and distance of the collecting units. Three different scenarios were defined by varying the location and the number of aggregating points in the field to show how much operational efficiency can be achieved based on these changes. Figure 15 demonstrates these three (A, B, C) scenarios with 10 dropping lines in the field. The yellow points represent the location of aggregating points in the field.

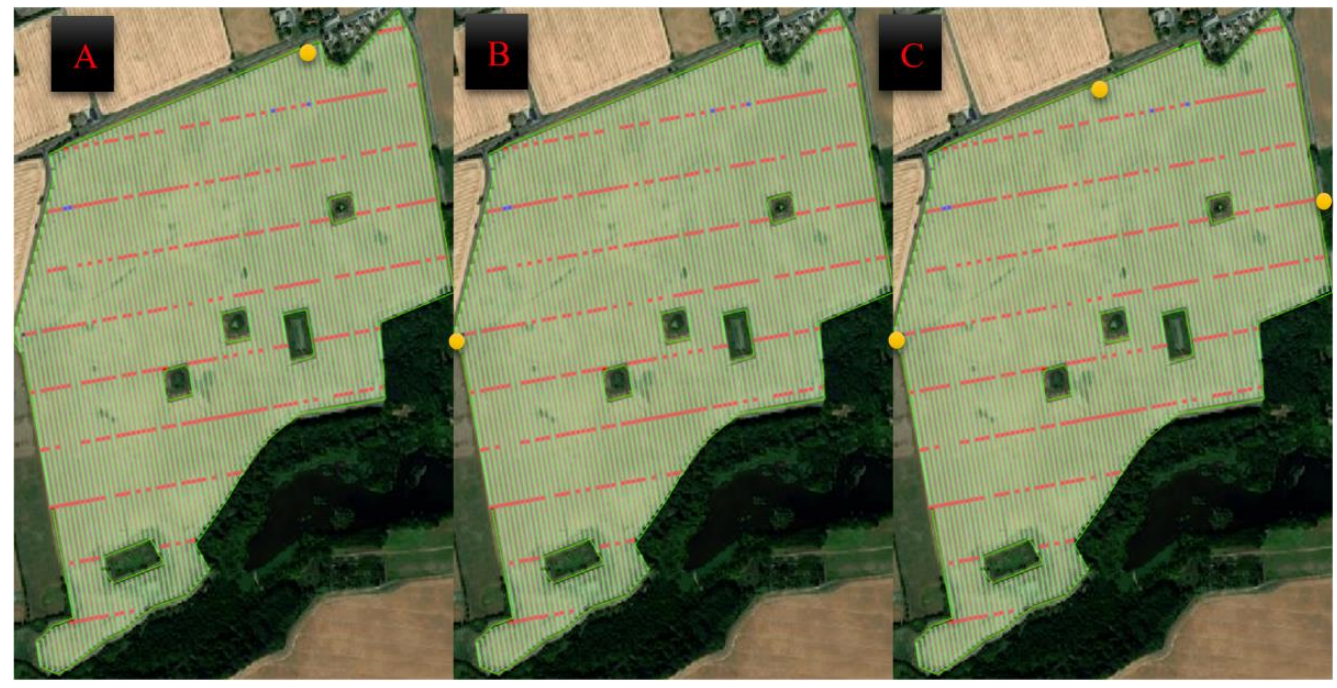

Figure 15. Defined scenarios based on the different locations for aggregating points in the field (with 10 dropping lines).

The results of the simulation model for collecting units are presented in Table 6. The comparison of scenarios in Figure 16 shows that varying the location of the aggregating point can increase operational efficiency by $9 \%$. Moreover, the results illustrate that increasing the number of aggregating points can reduce the collector's traveled distance and time. Three aggregating points in the third scenario increase operational efficiency by $44 \%$ in comparison with the first scenario with one aggregating point in the field. 
Table 6. Comparison of scenarios based on the location of the aggregating point for the collector.

\begin{tabular}{ccc}
\hline Scenarios & $\begin{array}{c}\text { Non-Working } \\
\text { Time (Minutes) }\end{array}$ & $\begin{array}{c}\text { Non-Working } \\
\text { Distance (Meter) }\end{array}$ \\
\hline 1 & 350.8 & 65,247 \\
2 & 319.2 & 59,366 \\
3 & 196 & 36,456 \\
\hline
\end{tabular}

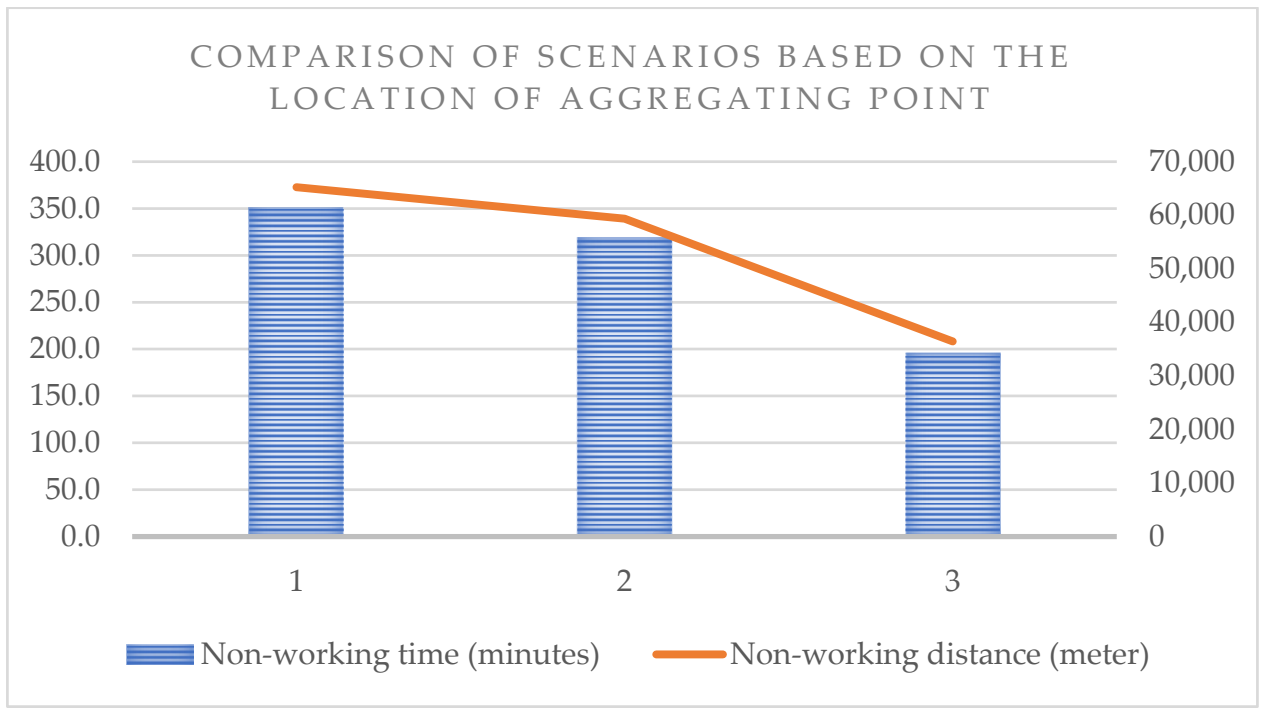

Figure 16. The comparison of the collector's travel time and distance for defined scenarios based on the location of aggregating points in the sample field.

\section{Discussion}

The minimum number of dropping lines in the sample field can be calculated as follows: First of all, the straw in the headland part of the sample field was chopped by a combine harvester, and there is no swath in this part for the baler. Therefore, the headland is taken out and the corrected field area is equal to 68.70 hectares. The straw yield is estimated based on the harvest index and crop yield and is equal to 3.21 (ton/ha). The number of produced bales can be estimated based on Equation (1) and it is equal to 380 bales. The traveled distance for producing one bale inside the field can be determined according to the Equation (2) and it is equal to $172 \mathrm{~m}$. Therefore, the minimum number of divisions for the longest track in the field is equal to two. By continuing the process of division for all the tracks, at the end there are a minimum of four dropping lines in total for the sample field. Other options with more than 10 dropping lines result in the same amount of baler non-working distance as 10 lines. Therefore, in this paper between 4 and 10 lines were considered as the options for the number of dropping lines in the sample field.

The results of the simulation model for traveled time and distance corresponding to the different number of dropping lines show that, by increasing the number of lines from 4 to 10, the amount of traveled time and distance is reduced. The reason behind this fact is that when the baler reaches the end of one track, based on the remaining capacity, there are limited options to choose for the next node for visiting to be sure that there is enough capacity to reach the next dropping line. As many divisions as there are in the tracks, there are many more options for the baler to choose from. Therefore, when there are at least 10 dropping lines in the sample field, the baler can follow the optimal route and at the same time, it can drop the bales on the dropping lines.

The comparison of simulation results for collecting units shows that based on the distance from dropping lines to the depot (aggregating point), the total traveled time and distance vary. In the first scenario, dividing the sample field into two halves with a 
horizontal line can better show how many bales are located in the north part of the field and closer to the depot.

Location of aggregating points can affect the traveled time and distance of collecting units inside the field. As can be seen in scenario A (Figure 15), the depot is located north of the field, and it is too far from those bales that are located on the lower dropping lines. Changing the location of the aggregating point in scenario $B$ reduces the amount of driving distance and time by the collecting units since the distance between the dropping lines and the depot is shorter in this scenario. Moreover, adding two more aggregating points in a different part of the field and close to the main road can reduce the traveled distance and time by $44 \%$.

In this study, a self-propelled and self-loading bale collector was considered for infield hauling operation. The capacity of this machine is eight bales for each load. The collecting process is carried out continuously and without stops and with a relatively high working speed (7 miles per hour). Other in-field hauling options such as bale loader and transporting wagons can be used. The capacity of these transporting wagons exceeds the capacity of the applied in-field hauling unit. However, due to the heavy weight of these wagons, they are quite slow. Moreover, these types of collecting units have a reduced capacity and the operator of the bale loader needs to have a special skill to do this operation efficiently.

There are different strategies and patterns for dropping the bales on the field during the collection of the residues along the fieldwork tracks. Clustering is a method in which the operator of the baler tries to drop the bales in a position where, at the end of covering the field, the bales are located closer to the center to form a cluster. After that, all the bales belong to a cluster aggregated in the center of that cluster. In the end, either all the aggregated bales in each cluster are directly transported to the biorefinery or they are transferred to the corner of the field closest to the road for further transportation. There is another method that tries to drop the bales as close to the headland part of the field as possible. Figure 11 shows that in this sample field, the operator of the baler tried to follow this method and drop the bales close to the headland part. The result shows that the proposed method in this study can bring higher efficiency $(12.9 \%)$ in comparison with that method.

One of the challenges in collecting the bales inside the big fields where there are different elevations inside the fields is that sometimes it is so hard for the collecting units to find the location of scattered bales on the field. One of the benefits of the proposed method is that all the bales are located on a straight line and thus it is easy for the operator of the collecting units to collect them by driving straight through all the bales on a dropping line. Moreover, another benefit of this method is that it is possible to reduce the amount of traveled non-working distance in the field for the baler and collecting units. consequently, there is less fuel consumption and fewer greenhouse gas (GHG) emissions by applying this method in tandem with conventional methods.

Future perspectives include improving the presented method and providing a real time solution as well as the application of robotics in the baling system, especially how to apply a fleet of robots instead of collecting units to aggregate the bales and collect the residues from the field.

\section{Conclusions}

A route planning algorithm was developed for a baling system to find the optimal traversal sequence of fieldwork tracks to follow by baler and bale retriever to minimize the non-working driving distance in the field. A meta-heuristics algorithm, simulated annealing, was applied to solve the problem of finding the optimal location for dropping the bales inside the field and the optimal number of dropped bales in each position. The operations efficiency of the optimized plan generated by the proposed method in this study were compared with the conventional, non-optimized method used by baler operators. The results showed that applying this new method could reduce the non-working distance per 
hectare by $12.9 \%$. The proposed algorithm in this paper can be used as part of a decision support tool to facilitate the baling process by providing the location and the number of bales to drop on the field when the crop yield is known from, e.g., combine harvester digital yield monitoring. Future research will focus on improving the presented method and providing a real time solution as well as the application of a robotic solution to a baling system and how to use a fleet of robots instead of collecting units to aggregate the bales and collect the residues from the field.

Author Contributions: Conceptualization, M.V., M.N., and C.G.S.; methodology, M.V. and M.N.; software, M.V.; validation, M.V., M.N., and C.G.S.; formal analysis, M.V. and M.N.; investigation, M.V.; resources, M.N. and C.G.S.; data curation, M.V.; writing-original draft preparation, M.V.; writing-review and editing, M.V., M.N., and C.G.S.; visualization, M.V.; supervision, C.G.S.; project administration, C.G.S.; funding acquisition, C.G.S. All authors have read and agreed to the published version of the manuscript.

Funding: This research received no external funding.

Conflicts of Interest: The authors declare no conflict of interest.

$\begin{array}{ll}\text { Nomenclature } \\ \text { NBales : } & \text { Number of bales } \\ A_{h a}: & \text { Field area } \\ Y_{h a}: & \text { Dry biomass yield } \\ M_{b}: & \text { Bale dry mass } \\ \text { DBales : } & \text { Traveled distance to make one bale } \\ \text { TLS : } & \text { Total length of swaths } \\ S: & \text { Swath width } \\ \text { NBLS }: & \text { Number of bales in the longest swath } \\ \text { LLS : } & \text { The length of the longest swath } \\ \text { NLines : } & \text { Minimum number of virtual lines } \\ C: & \text { The capacity of bale collector } \\ \text { Lp }: & \text { The length of divided part of LLS } \\ L_{A B}: & \text { The length of line AB } \\ \text { NdivAB }: & \text { The number of divisions for line AB } \\ \text { slpProjL }: & \text { The slope of projected lines }\end{array}$

\section{References}

1. Wang, X.; Dietrich, J.P.; Lotze-Campen, H.; Biewald, A.; Stevanović, M.; Bodirsky, B.L.; Brümmer, B.; Popp, A. Beyond land-use intensity: Assessing future global crop productivity growth under different socioeconomic pathways. Technol. Forecast. Soc. Chang. 2020, 160, 120208. [CrossRef]

2. Vahdanjoo, M.; Zhou, K.; Sørensen, C.A.G. Route planning for agricultural machines with multiple depots: Manure application case study. Agronomy 2020, 10, 1608. [CrossRef]

3. Perea-Moreno, M.-A.; Samerón-Manzano, E.; Perea-Moreno, A.-J. Biomass as renewable energy: Worldwide research trends. Sustainability 2019, 11, 863. [CrossRef]

4. Shah, S.A.R.; Naqvi, S.A.A.; Riaz, S.; Anwar, S.; Abbas, N. Nexus of biomass energy, key determinants of economic development and environment: A fresh evidence from Asia. Renew. Sustain. Energy Rev. 2020, 133, 110244. [CrossRef]

5. Pierossi, M.A.; Bertolani, F.C. Sugarcane trash as feedstock for biorefineries. Adv. Sugarcane Biorefinery 2018, 2018, 17-39. [CrossRef]

6. Zahedi, A.R.; Mirnezami, S.A. Experimental analysis of biomass to biodiesel conversion using a novel renewable combined cycle system. Renew. Energy 2020, 162, 1177-1194. [CrossRef]

7. Pantaleo, A.; Villarini, M.; Colantoni, A.; Carlini, M.; Santoro, F.; Hamedani, S.R. Techno-economic modeling of biomass pellet routes: Feasibility in Italy. Energies 2020, 13, 1636. [CrossRef]

8. Sun, O.; Fan, N. A review on optimization methods for biomass supply chain: Models and algorithms, sustainable issues, and challenges and opportunities. Process. Integr. Optim. Sustain. 2020, 4, 203-226. [CrossRef]

9. Subhashree, S.N.; Igathinathane, C.; Bora, G.C.; Ripplinger, D.; Backer, L. Optimized location of biomass bales stack for efficient logistics. Biomass Bioenergy 2017, 96, 130-141. [CrossRef] 
10. Igathinathane, C.; Tumuluru, J.S.; Keshwani, D.; Schmer, M.; Archer, D.; Liebig, M.; Halvorson, J.; Hendrickson, J.; Kronberg, S. Biomass bale stack and field outlet locations assessment for efficient infield logistics. Biomass Bioenergy 2016, 91, 217-226. [CrossRef]

11. Mafakheri, F.; Nasiri, F. Modeling of biomass-to-energy supply chain operations: Applications, challenges and research directions. Energy Policy 2014, 67, 116-126. [CrossRef]

12. Albashabsheh, N.T.; Stamm, J.L.H. Optimization of lignocellulosic biomass-to-biofuel supply chains with mobile pelleting. Transp. Res. Part E Logist. Transp. Rev. 2019, 122, 545-562. [CrossRef]

13. Melis, E.; Vincis, A.; Orrù, P.F. An overview of current models and approaches to biomass supply chain design and management. Curr. Sustain. Energy Rep. 2018, 5, 138-149. [CrossRef]

14. Hong, J.-D.; Mwakalonge, J.L. Biofuel logistics network scheme design with combined data envelopment analysis approach. Energy 2020, 209, 118342. [CrossRef]

15. Okuno, F.M.; Cardoso, T.D.F.; Duft, D.G.; Luciano, A.C.D.S.; Neves, J.L.M.; Soares, C.C.D.S.P.; Leal, M.R.L.V. Technical and economic parameters of sugarcane straw recovery: Baling and integral harvesting. Bioenergy Res. 2019, 12, 930-943. [CrossRef]

16. Salam, A.; Raza, U. Decision Agriculture. In Signals in the Soil, 1st ed.; Springer International Publishing: Berlin/Heidelberg, Germany, 2020; pp. 357-378. [CrossRef]

17. Segarra, J.; Buchaillot, M.L.; Araus, J.L.; Kefauver, S.C. Remote sensing for precision agriculture: Sentinel-2 improved features and applications. Agronomy 2020, 10, 641. [CrossRef]

18. Ampatzidis, Y.; Partel, V.; Costa, L. Agroview: Cloud-based application to process, analyze and visualize UAV-collected data for precision agriculture applications utilizing artificial intelligence. Comput. Electron. Agric. 2020, 174, 105457. [CrossRef]

19. García, L.; Parra, L.; Jimenez, J.M.; Lloret, J.; Lorenz, P. IoT-based smart irrigation systems: An overview on the recent trends on sensors and IoT systems for irrigation in precision agriculture. Sensors 2020, 20, 1042. [CrossRef]

20. Flak, J. Technologies for sustainable biomass supply-Overview of market offering. Agronomy 2020, 10, 798. [CrossRef]

21. Igathinathane, C.; Archer, D.; Gustafson, C.; Schmer, M.; Hendrickson, J.; Kronberg, S.; Keshwani, D.; Backer, L.; Hellevang, K.; Faller, T.; et al. Biomass round bales infield aggregation logistics scenarios. Biomass Bioenergy 2014, 66, 12-26. [CrossRef]

22. Malladi, K.T.; Sowlati, T. Biomass logistics: A review of important features, optimization modeling and the new trends. Renew. Sustain. Energy Rev. 2018, 94, 587-599. [CrossRef]

23. Grisso, R.; Cundiff, J.; Comer, K. Multi-bale handling unit for efficient logistics. AgriEngineering 2020, 2, 336-349. [CrossRef]

24. Zamar, D.; Gopaluni, B.; Sokhansanj, S. A Constrained K-Means and Nearest Neighbor Approach for Route Optimization in the Bale Collection Problem. IFAC-PapersOnLine 2017, 50, 12125-12130. [CrossRef]

25. Gracia, C.; Diezma-Iglesias, B.; Barreiro, P. A hybrid genetic algorithm for route optimization in the bale collecting problem. Span. J. Agric. Res. 2013, 11, 603. [CrossRef]

26. Bochtis, D.; Sørensen, C.; Busato, P.; Berruto, R. Benefits from optimal route planning based on B-patterns. Biosyst. Eng. 2013, 115, 389-395. [CrossRef]

27. Jensen, M.; Bochtis, D.; Sørensen, C. Coverage planning for capacitated field operations, part II: Optimisation. Biosyst. Eng. 2015, 139, 149-164. [CrossRef]

28. Khosravani Moghadam, E.; Vahdanjoo, M.; Jensen, A.; Sharifi, M.; Sørensen, C. An Arable Field for Benchmarking of Metaheuristic Algorithms for Capacitated Coverage Path Planning Problems. Agronomy 2020, 10, 1454. [CrossRef]

29. Paraforos, D.; Hübner, R.; Griepentrog, H. Automatic determination of headland turning from auto-steering position data for minimising the infield non-working time. Comput. Electron. Agric. 2018, 152, 393-400. [CrossRef]

30. Vahdanjoo, M.; Madsen, C.; Sørensen, C. Novel Route Planning System for Machinery Selection. Case: Slurry Application. AgriEngineering 2020, 2, 408-429. [CrossRef]

31. Conesa-Muñoz, J.; Bengochea-Guevara, J.; Andujar, D.; Ribeiro, A. Route planning for agricultural tasks: A general approach for fleets of autonomous vehicles in site-specific herbicide applications. Comput. Electron. Agric. 2016, 127, 204-220. [CrossRef]

32. Python Programming Language. Python Software Foundation. Available online: https:/ /www.python.org (accessed on 1 April 2020).

33. Rachmawati, D.; Gustin, L. Analysis of Dijkstra's Algorithm and A* Algorithm in Shortest Path Problem. J. Phys. Conf. Ser. 2020 1566, 012061. [CrossRef] 